\title{
INELASTIC STABILITY ANALYSIS FOR FRAMED STRUCTURES SUBJECTED TO NONCONSERVATIVE FORCES
}

\author{
Nam-Il Kim ${ }^{1}$ and Dong-Ho Choi ${ }^{2} *$ \\ ${ }^{I}$ Department of Architectural Engineering, Sejong University, \\ 98 Kunja Dong, Kwangjin Ku, Seoul 143-747, S. Korea \\ ${ }^{2}$ Department of Civil and Environmental Engineering, Hanyang University, \\ 17 Haengdang-dong, Seoungdong-gu, Seoul, 133-791, South Korea \\ *(Corresponding author: E-mail: samga@hanyang.ac.kr)
}

Received: 5 November 2011; Revised: 1 June 2012; Accepted: 8 June 2012

\begin{abstract}
In this study, the inelastic system buckling analysis is developed to evaluate the buckling loads and the effective length factors for columns in steel frames subjected to nonconservative forces. For this purpose, the finite element model for the nonconservative system is presented based on an extended Hamilton principle. The traditional elastic and inelastic stability analyses are briefly introduced for the conservative systems. Then evaluation procedure for the critical value of buckling load and its corresponding effective length factor for the nonconservative system are proposed based on the inelastic system buckling approach. In numerical examples, the buckling loads and the effective length factors for the inelastic conservative or nonconservative steel frames are evaluated and compared with results by other researchers. Particularly, the effects of various parameters such as the nonconservativeness parameter, the stiffness and span ratios of beam to column of frames on the inelastic stability behavior of nonconservative systems are newly addressed.
\end{abstract}

Keywords: Effective length factor, Inelastic column, Nonconservative force, Finite element method

\section{INTRODUCTION}

For decades, many researchers have explored various approaches for assessing column and frame stability in the design of steel structures. Among these approaches, the stability design method based on the effective length factor ( $K$-factor) was quite a common practice to engineers for many years.

Up to the present, various methods have been reported for the evaluation of $K$-factor and the most widely accepted method is the alignment chart method that was proposed by Julian and Lawrence [1]. And now, various design codes such as AISC [2], ACI [3], and AASHTO [4] adopt this method. The isolated subassembly approach, as an alternative method, has also been applied extensively following the early works of Galambos [5] and adopted in specifications such as DIN 18800 [6] and Eurocode 3 [7]. These alignment chart method and isolated subassembly approach are the traditional methods used to assess the rotational end restraints of the isolated column, which represent the stiffness ratio between the column and the beam. However in spite of its popularity, these approaches have major drawback in that they do not properly reflect the interaction effects of neighboring members except for the very closely adjacent columns and beams. Since these approaches are based on several fundamental assumptions, which basically limit the use of these methods only for the idealized cases, they may lead to inadequate estimation of the $K$-factor when these assumptions are not satisfied. To overcome this drawback, many studies have been carried out. Duan and Chen $[8,9]$ evaluated the $K$-factor of the three-story subassemblage of the frame using the same assumptions as the traditional effective length method, but considering the true boundary conditions at far ends of the top and bottom columns. The story-interaction of columns in no-sway frames was studied by Bridge and Fraser [10] and they extended the nomograph for effective lengths of non-sway buckling to a range where the rotational spring had a negative rigidity and proposed an iterative approach to calculate this interaction. Mahini and Seyyedian [11] presented a new iterative approach with a high convergence 
rate to improve the effectiveness of the $G$-factor method developed by Bridge and Fraser [10]. They replaced the explicit forms of the stability functions by more simple rational forms using the curve-fitting principles and converted members with the non-hinged far-end condition to the equivalent hinged far-end ones, considering the rotational stiffness in each case. The improved analytical expressions for $K$-factors of columns in multi-story sway frames were also proposed by Gantes and Mageirou [12]. They considered all possible rotational and translational boundary conditions at the far end of theses members, as well as the eventual presence of axial force.

Another improved approach to evaluate the $K$-factor is the so called "story-based approach" which accounts for the horizontal interaction between columns in a story. In the Commentary of the AISC [2], two methods of determining the story-based $K$-factor, namely the story buckling method [13] and the story stiffness method [14,15], were presented. LeMessurier [14,15] provided comprehensive discussion for story stability behavior and proposed a practical approach for obtaining $K$-factors to consider the story stability behavior. Also the in-plane buckling characteristics of the unbraced frames under the non-proportional loading adopting the story-based buckling concept were investigated by Xu et al. [16]. To get over the difficulty associated with the non-proportional loading, the problem of the lateral buckling of unbraced frames was expressed as a minimization problem subjected to stability constraints. Liu and $\mathrm{Xu}$ [17] presented a practical method for evaluating $K$-factors for columns in multi-story unbraced frames based on the story-based buckling concept, which decomposes a multi-story frame into a series of single-story partially-restrained frames.

The stability of the column in the frame structures, although often expressed as a stability problem restricted to an individual column, can be regarded as a problem in related with the whole stability of the structures by considering interactions between all members. Thus the column design is a system-related problem, not an individual member-restricted problem. Özmen and Girgin [18] developed the method for determining $K$-factors of columns in multi-story frames based on computing on approximate values for system buckling load by using the results of a fictitious lateral loading. Girgin et al. [19] applied their previous method [18] to irregular frames and obtained good results with errors less than 5\% for all examples considered. Geschwindner [20] reviewed a wide range of analytical approaches including the elastic system buckling analysis and Roddis et al. [21] pointed out the practical limitations of the alignment chart method using the elastic system buckling analysis. Despite significant achievements, all of these studies were devoted only to the elastic stability of the overall frame systems and did not consider the inelastic effects of columns.

To account for the effects of inelastic behavior on evaluation of $K$-factor, several researchers have studied the inelastic stability design of steel structures. Yura [13] proposed an iterative procedure to determine the $K$-factor in the inelastic range of column behavior. Choi et al. [22] presented the numerical method determining the inelastic effective length of each member in three-dimensional steel frames based on iterative schemes and the stiffness reduction factors considering a fictitious axial force factor. Kim and Lee [23] investigated the influence of the $P$ - $\Delta$ effect on the behavior of middle-rise unbraced steel frames using the refined plastic hinge method with an arc length algorithm. Essa [24] developed a design approach, to predict $K$-factors for columns in unbraced frames, considering the inelastic behavior, semi-rigid connections, far-end conditions, and differentiated stiffness parameters of the connected columns. He used a slope-deflection equation with the column stiffness reduction factors, which were evaluated from the column-strength curve proposed by the Structural Stability Research Council (SSRC) [25]. In AISC [2], inelastic $K$-factors are determined from the alignment chart method with the stiffness reduction factor applied to elastic modulus in the equation for $G$-factor. Depending on how the stiffness reduction factors are calculated, they might account for both the reduction in the stiffness of columns due to geometric imperfections and the spread of plasticity due to residual stresses under high compression loading. However, these studies 
were based on the alignment chart method, which adopted several simplifying assumptions and restricted to the stability analysis of frames under the conservative forces.

The nonconservative forces are forces whose line of action is affected by the deformation of the system on which they act and some examples of the nonconservative systems are the frame structures, the members of bridges, and aircraft which are subjected to aerodynamic force. The submarines and ships are also subjected to hydrodynamic forces which are nonconservative. The nonconservative forces are present in basically every engineering field such as civil engineering and bioengineering (spinal chord) among others and considerable attention has been devoted to the stability of columns subjected to these nonconservative forces. The first review of this branch of applied mechanics has been made in a book form by Bolotin [26]. Gasparini et al. [27] discussed the transition between the stability and instability of a cantilevered beam subjected to the partially follower force. Ryu et al. [28] employed the finite element method to perform the numerical analyses on the stability of a cantilevered column subjected to the triangulary distributed subtangential forces. Wang [29] studied the effect of the follower force on the buckling capacities of the beam structure subjected to the concentrated follower force. Imielowski [30] performed the sensitivity analysis of a stepped column under the subtangential force depending on the nonconservativeness parameter and investigated the influence of joint stiffness, variation of segment cross-sections and their length. But these works only dealt with the elastic stability problems of a single column under the nonconservative forces. Lee $e t$ al. [31] investigated the dynamic stability behavior of the Beck's column resting on elastic foundation by using the finite element method.

From the previously cited references, it can be noted that even though a significant amount of research has been extensively conducted on the evaluation of $K$-factor for the stability design of frames, there still has been no study reported on the elastic or inelastic instability analyses of steel frames subjected to nonconservative forces. The main purpose of this study is to present a more reliable procedure to determine $K$-factors of columns in steel frames subjected to nonconservative forces based on the elastic and inelastic system buckling analyses by using the column strength curves. The important points considered in this study are summarized as follows:

1. Based on the extended Hamilton principle, the finite element model is formulated. For this, the generalized displacements are expressed over each element as a linear combination of the onedimensional Lagrange interpolation function for the axial displacement and the cubic Hermite interpolation function for the lateral displacement.

2. Traditional elastic and inelastic stability analyses such as the isolated subassembly approach and the story-based one are briefly presented for the conservative systems.

3. Inelastic system buckling analysis procedure using the AISC-LRFD and Eurocode 3 column strength curves under nonconservative forces is proposed based on a nonlinear eigenvalue analysis algorithm.

4. To illustrate the accuracy and the effectiveness of the proposed method from numerical examples, buckling loads or $K$-factors of steel columns in frame structures subjected to the conservative or nonconservative forces are evaluated and compared with those by available references.

5. Especially, emphasis is given in showing the effects of the nonconservativenenss parameter, the stiffness and span ratios of beam to column on buckling loads. $K$-factors are also investigated for the inelastic nonconservative systems. 


\section{FINITE ELEMENT MODEL FOR NONCONSERVATIVE SYSTEM}

Figure 1 shows the cantilevered column of the length $L$ subjected to the combined conservative force $P_{c}$ and the tangential follower force $P_{t}$ acting at the tip. The former may be thought of as a dead load, while the latter can be considered as a typical follower force and the two forces $P_{c}$ and $P_{t}$ are assumed to be constant along the elastic line. For a small deflection, the angle between the $x$-axis and the tangent to the elastic line of column can be approximated by $\partial v / \partial x$ where $v$ is the lateral displacement. The direction of the resultant subtangential force $P$ is specified by $\alpha \partial v(L) / \partial x$. Thus the parameter $\alpha$ can also be referred to as the nonconservativeness parameter and one can easily derive the following relation.

$$
\mathbf{P}=\mathbf{P}_{\mathbf{c}}+\mathbf{P}_{\mathbf{t}}, \quad \alpha=\frac{P_{t}}{P}
$$

Note that the force is conservative for $\alpha=0$, while it is nonconservative for $\alpha \neq 0$ and is a purely tangential follower force for $\alpha=1$.

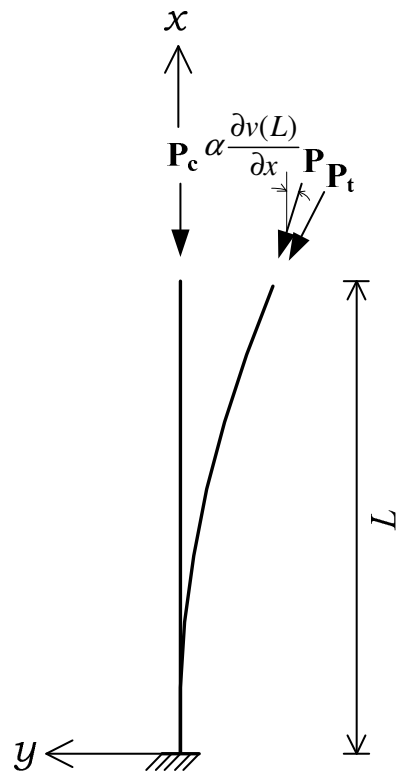

Figure 1. Column subjected to the Nonconservative Force

In order to present the finite element formulation of the element with the length $l_{e}$, three nodal displacements at nodal end points $p$ and $q\left(u^{p}, v^{p}, \theta^{p} ; u^{q}, v^{q}, \theta^{q}\right)$ are considered in which $u, v$ and $\theta$ are the axial displacement, the lateral displacement, and the angle of rotation, respectively. In this study, the strain energy $\Pi_{E}$ of the system, the potential energy $\Pi_{G}$ including the work done by the conservative component of the subtangential force and the virtual work $\delta \prod_{N C}$ by the nonconservative component of the acting force are considered. Here the type of instability is only divergence and the critical flutter load from the dynamic criterion is not considered. These terms are expressed as follows:

$$
\Pi_{E}=\sum_{e} \frac{1}{2} \int_{o}^{l_{e}}\left\{E_{t} A\left(\frac{\partial u}{\partial x}\right)^{2}+E_{t} I\left(\frac{\partial^{2} v}{\partial x^{2}}\right)^{2}\right\} d x
$$




$$
\begin{aligned}
& \Pi_{G}=-\sum_{e} \frac{1}{2} \int_{o}^{l_{e}} P\left(\frac{\partial v}{\partial x}\right)^{2} d x \\
& \delta \Pi_{N C}=-\alpha P \frac{\partial v(L)}{\partial x} \delta v(L)
\end{aligned}
$$

where $E_{t}$ is the tangent modulus; $A$ and $I$ are the cross-sectional area and the second moment of inertia, respectively; $\delta$ is the variation. The extended Hamilton principle of the column can be presented by

$$
\int_{t_{1}}^{t_{2}}\left[\delta\left(\Pi_{E}+\prod_{G}\right)-\delta \Pi_{N C}\right] d t=0
$$

The present column theory is implemented via a displacement-based finite element method. For this, the generalized displacements are expressed over each element as an one-dimensional Lagrange interpolation function for the axial displacement $u$ and the third-order Hermitian interpolation function for the lateral displacement $v$. By substituting the interpolated displacements into Eq. 3, the resulting equation for a single element is obtained in a matrix form as

$$
\int_{t_{1}}^{t_{2}}\left[\delta \mathbf{U}_{\mathbf{e}}\left(\mathbf{K}_{\mathbf{e}}+\mathbf{K}_{\mathbf{g}}-\mathbf{K}_{\mathbf{n c}}\right) \mathbf{U}_{\mathbf{e}}-\delta \mathbf{U}_{\mathbf{e}} \mathbf{F}_{\mathbf{e}}\right] d t=0
$$

where $\mathbf{U}_{\mathbf{e}}$ and $\mathbf{F}_{\mathbf{e}}$ are the nodal displacement and force vectors, respectively; $\mathbf{K}_{\mathbf{e}}$ and $\mathbf{K}_{\mathrm{g}}$ are the elastic stiffness matrix and the geometric stiffness matrix due to conservative compressive forces, respectively; $\mathbf{K}_{\mathbf{n c}}$ is the load correction stiffness matrix due to the directional change of nonconservative forces.

Finally, the equilibrium equation for whole column members is expressed in a matrix form using the direct stiffness method as follows:

$$
\left(\mathbf{K}_{\mathbf{E}}+\mathbf{K}_{\mathbf{G}}-\mathbf{K}_{\mathrm{NC}}\right) \mathbf{U}=\mathbf{F}
$$

where $\mathbf{K}_{\mathbf{E}}, \mathbf{K}_{\mathbf{G}}$, and $\mathbf{K}_{\mathbf{N C}}$ are respectively the elastic and geometric stiffness matrices, and the load correction stiffness matrix due to the nonconservative forces in the global coordinate system.

\section{TRADITIONAL ELASTIC AND INELASTIC STABILITY APPROACHES}

A wide range of methods have been suggested in the engineering literature for the design calculation of column buckling loads and their corresponding $K$-factors. This section outlines the broad categories of the traditional elastic and inelastic stability approaches based on the physical extent of the structure under the conservative forces.

\subsection{Isolated Subassembly Approach}

The effective length of an end-restrained column is defined as the length of an equivalent pined-ended column that will give the same critical load as the end-restrained column. This effective length can be visualized as the distance between the two inflection points (real and imaginary) of the buckled shape of the end-restrained member. The most widely used method for evaluating $K$-factor is probably the isolated subassembly approach, also commonly referred to as the alignment chart method or the $G$-factor method since it offers a straightforward method of obtaining $K$ of the column. 
The transcendental equations of the buckling solution of the subassemblage for the sideway inhibited and uninhibited frames subjected to conservative compressive forces are given in Eq. 6 and the detailed step-by-step derivation of equations governing the buckling of this assembly is presented by Chen and Lui [32] based on the slope deflection equations.

$$
\begin{aligned}
& \frac{G_{A} G_{B}}{4}\left(\frac{\pi}{K}\right)^{2}+\left(\frac{G_{A}+G_{B}}{2}\right)\left(1-\frac{\pi / K}{\tan (\pi / K)}\right)+\frac{2 \tan (\pi / 2 K)}{\pi / K}-1=0 \\
& \frac{G_{A} G_{B}(\pi / K)^{2}-36}{6\left(G_{A}+G_{B}\right)}-\frac{\pi / K}{\tan (\pi / K)}=0
\end{aligned}
$$

where $G_{A}$ and $G_{B}$ are the stiffness ratios ( $G$-factors) of columns and beams at joints $A$ and $B$, respectively, and the detailed expressions are as follows:

$$
G_{A}=\frac{\sum_{A}\left(E_{c} I_{c} / L_{c}\right)}{\sum_{A}\left(E_{b} I_{b} / L_{b}\right)} \quad \text { and } \quad G_{B}=\frac{\sum_{B}\left(E_{c} I_{c} / L_{c}\right)}{\sum_{B}\left(E_{b} I_{b} / L_{b}\right)}
$$

where subscript $c$ and $b$ denote the column and the beam, respectively. Note that Eq. 6 may be analytically derived under several fundamental assumptions that the structure should follow in order to guarantee a reasonable result.

It is well known that the significant economy may be gained by utilizing inelastic buckling solutions in many design situations $[13,15]$, although the column strength calculations are often based on the elastic models. This is because the slenderness of the columns in typical steel buildings is usually small enough such that the distributed yielding occurs along the column lengths before the design strength of the most critically-loaded components is reached. To reflect the inelastic effects into the design of steel frames, the elastic modulus can be lowered with the inelastic stiffness reduction factor $\tau_{a}$ as follows (AISC [2]):

$$
E_{t}=\tau_{a} E
$$

where

$$
\begin{aligned}
& \tau_{a}=1.0 \quad \text { for } \quad P_{n} / P_{y} \leq 0.39 \\
& \tau_{a}=-2.724\left(P_{n} / P_{y}\right) \ln \left(P_{n} / P_{y}\right) \text { for } \quad P_{n} / P_{y}>0.39
\end{aligned}
$$

where $E$ is the elastic modulus; $P_{n}$ and $P_{y}$ are the nominal column strength and the yielding axial force, respectively. Thus the inelastic $K$-factor can be determined by using $\tau_{a}$ times $E_{c}$ for $E_{c}$ in the equations for $G_{A}$ and $G_{B}$ in Eq. 7

\subsection{Story-based Approach}

Since the isolated subassembly approach assumes that the shear force of the column does not transfer to other columns in the same story, each of columns in any story buckles in the sidesway mode, independent of the adjacent columns. This assumption may be inadequate in some real cases, such as a structural system with leaning columns. To account for the interaction effect between the columns 
in the story, the inelastic $K$-factor can be inferred from the elastic $K$-factor which the commentary of AISC [2] recommends based on the story buckling method as follows:

$$
K=\sqrt{\frac{\pi^{2} \tau_{a} E I / L^{2}}{P_{r}}\left(\frac{\sum P_{r}}{\sum \frac{\pi^{2} \tau_{a} E I}{\left(K_{n 2} L\right)^{2}}}\right)} \geq \sqrt{\frac{5}{8}} K_{n 2}
$$

where $K_{n 2}$ is defined as the $K$ value determined directly from the alignment chart, $P_{r}$ is the required axial compressive force for the rigid column, and $\Sigma P_{r}$ is the total axial compressive force of columns in the story. The $K$-factor obtained from Eq. 10 inherently account for the inelastic effects and the interactions within and between stories at incipient buckling of the system subjected to conservative forces.

On the other hand, the story stiffness method considers later displacements of the story instead of the sum of the compressive force. The inelastic $K$-factor can be deduced from the Equation $\mathrm{C}-\mathrm{C} 2-5$ in AISC [2] as follows:

$$
K=\sqrt{\frac{\sum P_{r}}{\left(0.85+0.15 R_{L}\right) P_{r}}\left(\frac{\pi^{2} \tau_{a} E I}{L^{2}}\right)\left(\frac{\Delta_{H}}{\sum H L}\right)} \geq \sqrt{\frac{\pi^{2} \tau_{a} E I}{L^{2}}\left(\frac{\Delta_{H}}{1.7 H L}\right)}
$$

where $H$ and $\Delta_{H}$ are respectively the shear in the column and the lateral displacement of the story under consideration. $R_{L}$ is the ratio of the vertical column load for all leaning columns in the story to the vertical load of all the columns in the story expressed by

$$
R_{L}=\frac{\sum P_{r} \quad \text { leaning columns }}{\sum P_{r} \text { all columns }}
$$

\section{SYSTEM BUCKLING APPROACH UNDER NONCONSERVATIVE FORCES}

In this section, the elastic and inelastic system buckling approaches for calculating buckling loads and $K$-factors for columns in steel frames subjected to nonconservative forces are presented.

\subsection{Column Strength Curves for AISC-LRFD and Eurocode 3}

The inelastic buckling of columns can lead to system collapse prior to the formation of a plastic hinge on beam members as external loads are increased on the steel frames. In several design specifications, the load-carrying capacity of the column member is modified based on such information as theoretical buckling analysis results, various experimental results come from initial imperfections due to manufacturing or constructional errors, residual stress due to welding, dependency on cross-sectional shape and etc.

In this study, two kinds of load-carrying capacity curves are presented for further development in inelastic buckling formulation, one from the AISC-LRFD [33] and the other from the Eurocode 3 [7]. In the development of the LRFD specification, the AISC specification uses a column strength curve as 


$$
\begin{aligned}
& f^{*}=0.658^{\lambda^{* 2}} \quad \text { for } 0 \leq \lambda^{*} \leq 1.5 \\
& f^{*}=\frac{0.877}{\lambda^{* 2}} \quad \text { for } \quad \lambda^{*}>1.5
\end{aligned}
$$

where

$$
f^{*}=\frac{f_{c r}}{f_{y}}, \quad \lambda^{*}=\frac{K L}{\pi r} \sqrt{\frac{f_{y}}{E}}
$$

In which $f^{*}$ and $\lambda^{*}$ are the dimensionless strength of the column and the slenderness parameter, respectively; $f_{c r}$ and $f_{y}$ are the critical buckling stress and the specified minimum yield stress, respectively; $r$ the governing radius of gyration about the axis of bucking. This equation was calibrated to fit closely the SSRC curve 2 [34], which was modified to reflect an initial out-of-straightness of about 1/1500. This strength curve of AISC-LRFD [33] is depicted in Figure 2 together with the Euler hyperbola curve and the strength curves of Eurocode 3 [7].

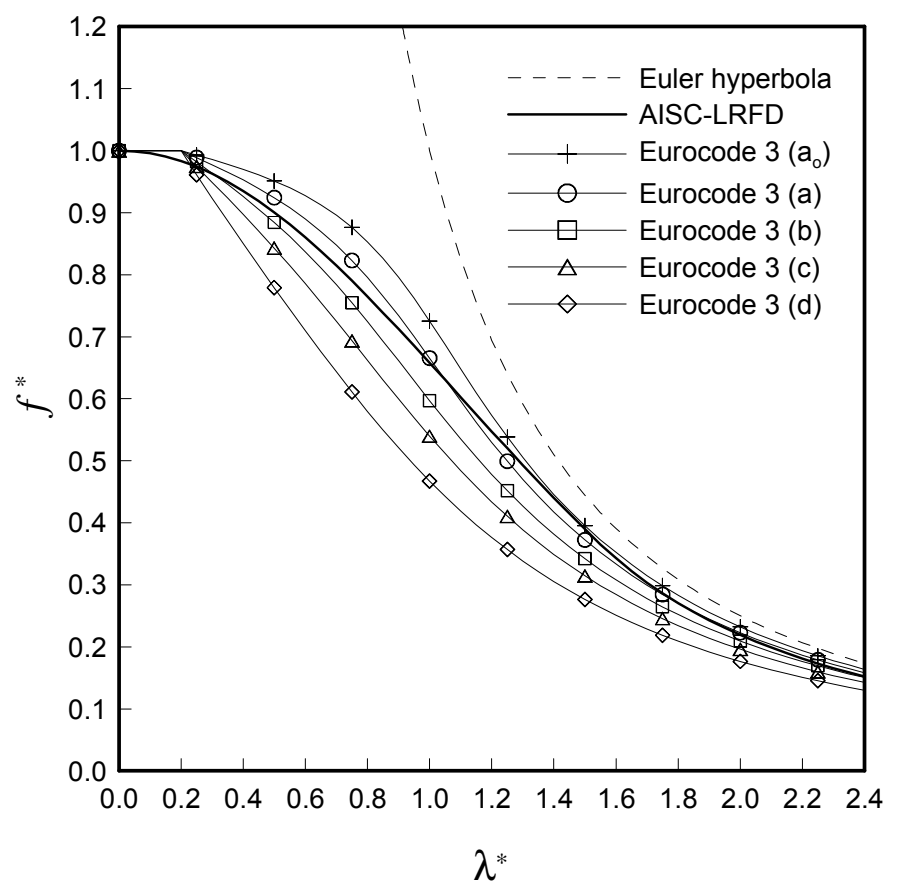

Figure 2. Load-carrying Capacity Curves in AISC-LRFD and Eurocode 3

The simplified design predictions for the maximum load (or resistance) were also used in Eurocode 3 [7] that had been developed from the results of computer analyses and correlations with available test data considering the residual stresses and the initial imperfection in design of compression members. The Eurocode 3 approach to determine the buckling resistance of compression member is based on the same principles as that of BS 5950 [35]. Although minor technical differences exist, the primary difference between the two codes is in the presentation of the method. The basic formulations for buckling curves are given by

$$
f^{*}=\frac{1}{\phi+\sqrt{\phi^{2}-\lambda^{* 2}}} \quad \text { but } \quad f^{*} \leq 1.0
$$

where 


$$
\phi=0.5\left[1+\beta\left(\lambda^{*}-0.2\right)+\lambda^{* 2}\right]
$$

In which $\beta$ is the imperfection factor which shifts the resistance curve, as shown in Figure 2, for different cross-section types, properties, thicknesses, buckling axes, and material strengths and the five values of $\beta$ for each of these curves are given in Table 1. The advantage of this approach is that the buckling resistances of a particular group of sections can be determined by assigning an appropriate value of $\beta$ to them.

Table 1. Imperfection Factors for Buckling Curves

\begin{tabular}{cccccc}
\hline Buckling curve & $a_{o}$ & $a$ & $b$ & $c$ & $d$ \\
\hline Imperfection factor $\beta$ & 0.13 & 0.21 & 0.34 & 0.49 & 0.76 \\
\hline
\end{tabular}

\subsection{Elastic and Inelastic System Buckling Analyses}

According to the study by Chen and Lui [32], the best way to evaluate the more accurate $K$-factor for each individual member of the frame structure should be the stability analysis of the entire structure as a whole. The followings describe the elastic and inelastic system buckling analysis procedure proposed by this study.

Step 1) Constitute the system elastic stiffness matrix $\mathbf{K}_{\mathbf{E}}$ for the whole structure. For a given load condition, the following linear elastic analysis is performed from Eq. 5 to evaluate the axial force $P_{j}$ for each member where subscript $j$ denotes the number of member.

$$
\mathbf{K}_{\mathbf{E}} \mathbf{U}=\mathbf{F}
$$

Step 2) Solve the linear eigenvalue problem in Eq. 18 and calculate the minimum eigenvalue $\xi_{c r}^{i}$ where superscript $i$ means the number of iteration.

$$
\mathbf{K}_{\mathbf{E}}^{i}\left(E_{t}^{i}\right) \Delta \mathbf{U}=\xi_{c r}^{i}\left(\mathbf{K}_{\mathbf{G}}^{i}-\mathbf{K}_{\mathbf{N C}}^{i}\right) \Delta \mathbf{U}
$$

Then the elastic buckling load of each member is calculated as $\xi_{c r}^{i} P_{j}$.

Step 3) Evaluate the slenderness parameter $\lambda_{j}^{* i}$ of each member as follows:

$$
\lambda_{j}^{* i}=\frac{L_{e}^{i}}{\pi r} \sqrt{\frac{f_{y}}{E}}
$$

where the effective length is defined as

$$
L_{e}^{i}=K^{i} L=\pi \sqrt{\frac{E_{t, j}^{i} I_{j}}{\xi_{c r}^{i} P_{j}}}
$$

Step 4) Calculate the inelastic critical buckling stress $f_{c r, j}^{i}$ of each member from the AISC-LRFD and Eurocode 3 column strength curves by utilizing the slenderness parameter $\lambda_{j}^{* i}$. 
Step 5) Calculate the refined tangent modulus of each member as

$$
E_{t, j}^{i+1}=\frac{f_{c r, j}^{i}}{f_{c r, i n, j}^{i}} E_{t, j}^{i}
$$

where $f_{c r, i n, j}^{i}$ is the inelastic buckling stress of each member obtained from Eq. 18. Next check the convergence designated as $\left(E_{t, j}^{i+1}-E_{t, j}^{i}\right) / E_{t, j}^{i}<\varepsilon$. In case that the convergence is not achieved, go back to the step 2).

Step 6) Determine the final $K$-factor of each member.

In addition, Figure 3 shows the schematic procedures for the evaluation of $K$-factor in inelastic stability analysis.

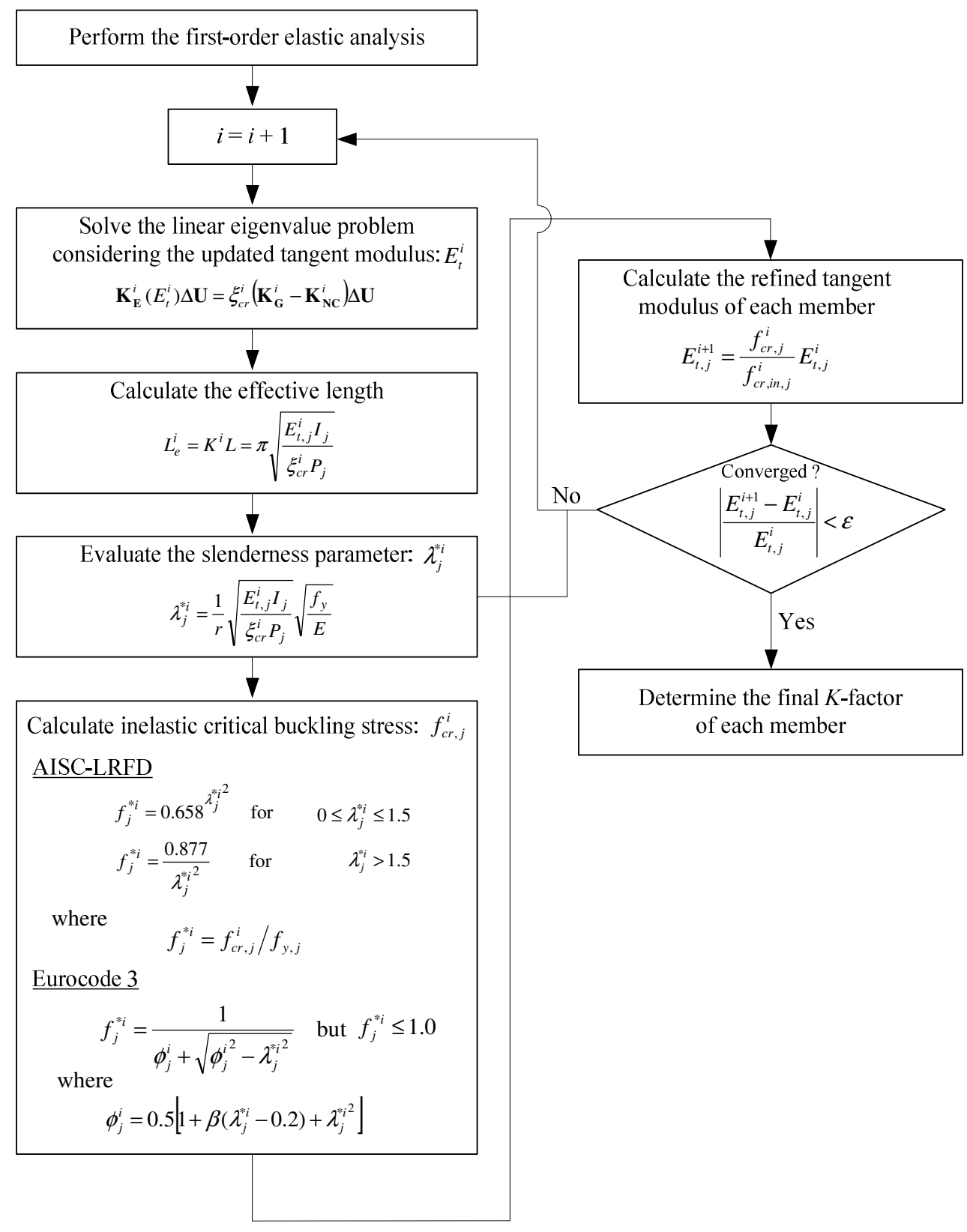

Figure 3. Flowchart of the Evaluation of $K$-factor in Inelastic Stability Analysis 


\section{NUMERICAL EXAMPLES}

In numerical examples, to show the accuracy and the usefulness of the present study, the elastic and inelastic stability analyses of the frame structures subjected to conservative or nonconservative forces are performed and compared with other available references. The effects of various parameters on buckling loads and $K$-factors for columns in steel frames are investigated. In subsequent examples, each column is modeled with the five finite beam elements and the yield stress $f_{y}$ of all columns is 344.7 MPa (50 ksi).

\subsection{Three-story Frame Subjected to Conservative Forces}

The stability analysis is carried out on the three-story frame subjected to conservative forces to illustrate the validity of the present method to predict $K$-factors of columns. Figure 4 shows the configuration of the frame with $\mathrm{W}$-shape section, and its material and sectional properties are as follows: $E=2 \times 10^{5} \mathrm{MPa}$; W8 $\times 35: A=6.645 \times 10^{-3} \mathrm{~m}^{2}, I=5.286 \times 10^{-5} \mathrm{~m}^{4} ; \mathrm{W} 8 \times 48: A=9.097 \times 10^{-3} \mathrm{~m}^{2}$, $I=7.659 \times 10^{-5} \mathrm{~m}^{4} ; \mathrm{W} 14 \times 30: A=5.71 \times 10^{-3} \mathrm{~m}^{2}, I=1.2112 \times 10^{-4} \mathrm{~m}^{4} ; \mathrm{W} 21 \times 44: A=8.387 \times 10^{-3} \mathrm{~m}^{2}, I$ $=3.5088 \times 10^{-4} \mathrm{~m}^{4}$. The $K$-factors evaluated by present elastic and inelastic stability analyses are presented in Table 2. For comparison, the $K$-factors by Liu and $\mathrm{Xu}$ [17] who uses the geometrical stiffness distribution approach for elastic analysis and AISC [2] using the modified equation for determining $K$-factors based on the story buckling approach and the alignment chart method for elastic and inelastic analyses are presented. It can be seen that the results by the present Euler hyperbola curve show fairly good agreement with those by Liu and $\mathrm{Xu}$ [17]. When the inelastic behavior is considered, the $K$-factor for column $\mathrm{C}_{1}$, on which the highest axial force acts, becomes smaller. On the other hand, the inelastic system buckling analysis introduces the higher $K$-factor for column $\mathrm{C}_{3}$ having the relatively small axial force.

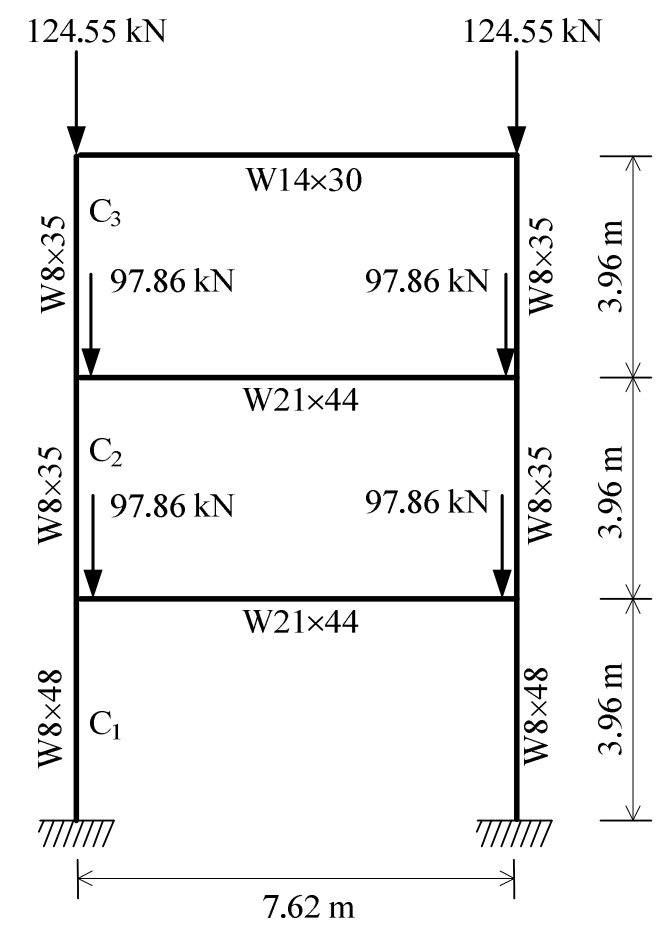

Figure 4. Three-story Frame subjected to Conservative Forces 
Table 2. $K$-factors of the Three-story Frame Subjected to Conservative Forces $(\alpha=0)$

\begin{tabular}{|c|c|c|c|c|c|c|}
\hline \multirow{2}{*}{ Methods } & \multicolumn{3}{|c|}{ Elastic analysis } & \multicolumn{3}{|c|}{ Inelastic analysis } \\
\hline & $\mathrm{C}_{1}$ & $\mathrm{C}_{2}$ & $\mathrm{C}_{3}$ & $\mathrm{C}_{1}$ & $\mathrm{C}_{2}$ & $\mathrm{C}_{3}$ \\
\hline Liu and Xu [17] & 1.15 & 1.15 & 1.53 & - & - & - \\
\hline Story buckling approach [2] & 1.11 & 1.21 & 1.23 & 1.07 & 1.14 & 1.21 \\
\hline Alignment chart method & 1.11 & 1.21 & 1.23 & 1.07 & 1.14 & 1.21 \\
\hline \multirow{3}{*}{ This study $\left\{\begin{array}{l}\text { Euler } \\
\text { hyperbola } \\
\text { AISC-LRFD } \\
\text { Eurocode 3 }\end{array}\right.$} & 1.15 & 1.14 & 1.53 & - & - & - \\
\hline & - & - & - & 1.03 & 1.11 & 2.31 \\
\hline & - & - & - & 1.03 & 1.10 & 2.13 \\
\hline
\end{tabular}

\subsection{Cantilevered Column}

For verification purpose of the present study in evaluation of buckling load for the column subjected to the nonconservative force, we consider the cantilevered column with W-shape section (W8 $\times 35$ ) subjected to the compressive tangential force $P$ acting at the top of the column as shown in Figure 1 . The length of column is $3 \mathrm{~m}$ and the material and sectional properties are as follows: $E=2 \times 10^{5} \mathrm{MPa}$, $A=6.645 \times 10^{-3} \mathrm{~m}^{2}, I=5.286 \times 10^{-5} \mathrm{~m}^{4}$. For simplicity the dimensionless buckling load $P_{c r}^{*}=$ $P_{c r} L^{2} /(E I)$, in which $P_{c r}$ denotes the critical buckling load, is introduced. In Table 3, the dimensionless buckling loads by this study are compared with results obtained by Rao and Rao [36] deriving the exact solutions, with the solutions given by Leipholz [37], and with those proposed by Kikuchi [38] via a finite element technique. It can be found from Table 3 that the results by this Euler hyperbola curve are in excellent agreement with other literature results for whole $\alpha$ considered.

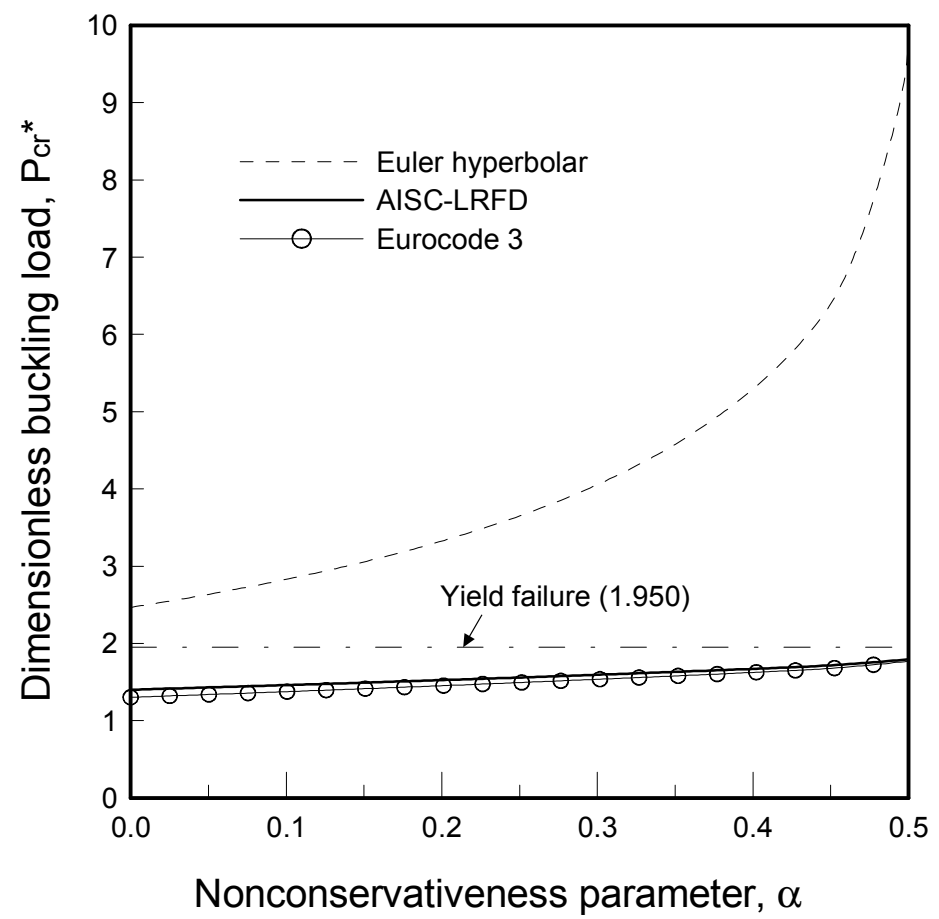

(a) Dimensionless buckling loads 


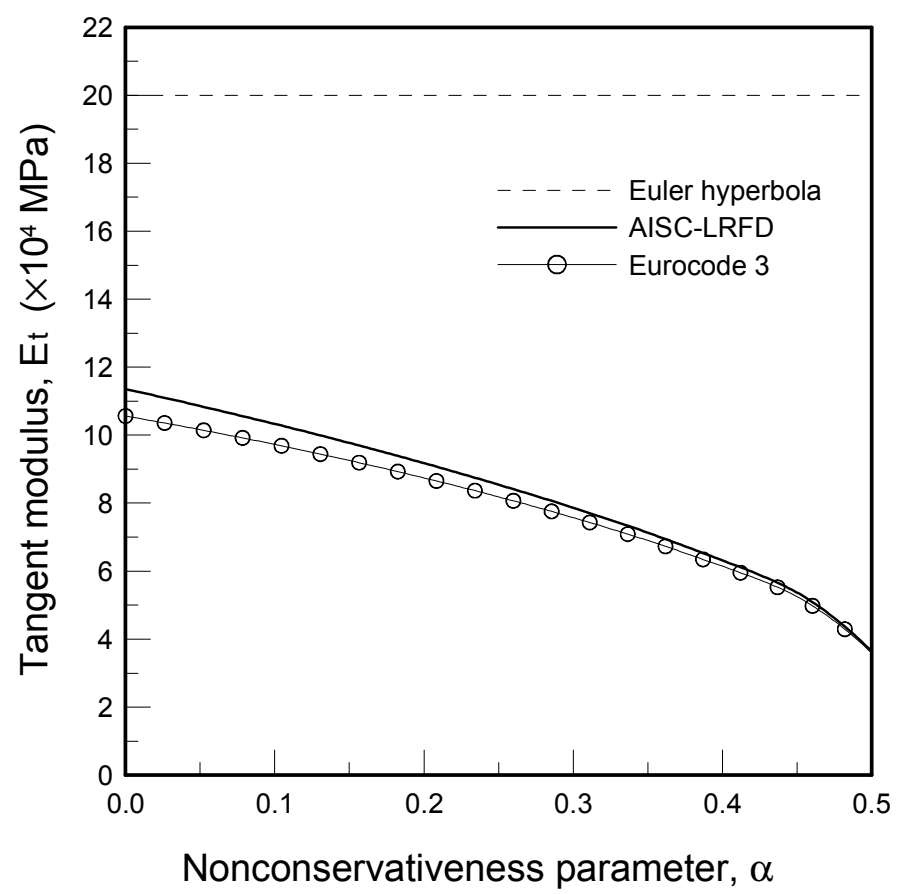

(b) Variation of the tangent modulus

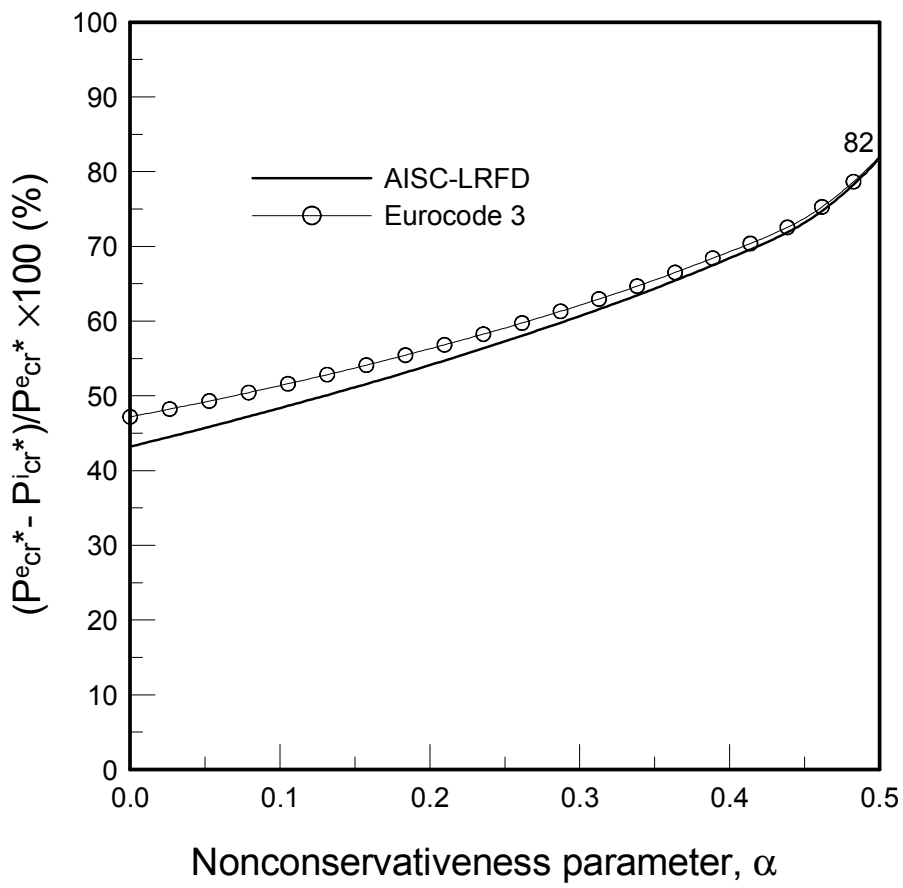

(c) Effects of inelasticity on the dimensionless buckling loads

Figure 5. Dimensionless Buckling Loads and Its Corresponding Tangent Modulus, and the Effects of Inelasticity on the Dimensionless Buckling Loads for the Cantilevered Column with Respect to $\alpha$ 
Table 3. Dimensionless Buckling Loads for the Cantilevered Column Subjected to the Nonconservative Force

\begin{tabular}{|c|c|c|c|c|c|c|}
\hline \multirow{2}{*}{ Methods } & \multicolumn{6}{|c|}{ Nonconservativeness parameter $\alpha$} \\
\hline & 0.0 & 0.1 & 0.2 & 0.3 & 0.4 & 0.5 \\
\hline Rao and Rao [36] & 2.467 & 2.830 & 3.325 & 4.055 & 5.292 & 9.870 \\
\hline Leipholz [37] & 2.467 & 2.830 & 3.325 & 4.055 & 5.292 & 9.870 \\
\hline Kikuchi [38] & 2.467 & 2.830 & 3.325 & 4.055 & 5.293 & 9.872 \\
\hline $\int \begin{array}{l}\text { Euler } \\
\text { hyperbola }\end{array}$ & 2.467 & 2.830 & 3.325 & 4.055 & 5.293 & 9.871 \\
\hline AISC-LRFD & 1.401 & 1.461 & 1.526 & 1.595 & 1.671 & 1.795 \\
\hline Eurocode 3 & 1.303 & 1.376 & 1.453 & 1.536 & 1.625 & 1.771 \\
\hline
\end{tabular}

Figure 5(a) shows the variation of the dimensionless buckling loads with respect to $\alpha$. It can be observed from Figure 5(a) that the buckling loads from both elastic and inelastic stability analyses increase as $\alpha$ increases, so the conservative case $(\alpha=0)$ is the more susceptible of instability. Also the increase ratio of buckling load with respect to $\alpha$ for the Euler hyperbola curve is larger than those for AISC-LRFD and Eurocode 3 curves. As is expected, this is due to the fact that as $\alpha$ increases, the critical buckling loads from the inelastic stability analyses increases slowly with significant degradation of the tangent modulus as seen in Figure 5(b). In Figure 5(c), the inelastic effects on the dimensionless buckling load are plotted with $\alpha$. Here $P_{c r}^{e^{*}}$ and $P_{c r}^{i^{*}}$ denote the dimensionless buckling loads from the elastic and inelastic stability analyses, respectively. As the results show, the inelastic effects on the buckling loads increase as $\alpha$ increases up to around $82 \%$ at $\alpha=0.5$ for both of AISC-LRFD and Eurocode 3 curves.

\subsection{Frame with Semirigid Connections}

The frame with semirigid connections as shown in Figure 6 is considered. The frame consists of columns with W14 $\times 22$ section and the modulus of elasticity is $2 \times 10^{5} \mathrm{MPa}$. The moment of inertia for columns $\left(I_{c}\right)$ and beams $\left(I_{b 1}, I_{b 2}\right)$ are as follows: $I_{c}=82.83 \times 10^{-6} \mathrm{~m}^{4}, I_{b 1}=83.25 \times 10^{-6} \mathrm{~m}^{4}$, and $I_{b 2}=$ $10.41 \times 10^{-6} \mathrm{~m}^{4}$.

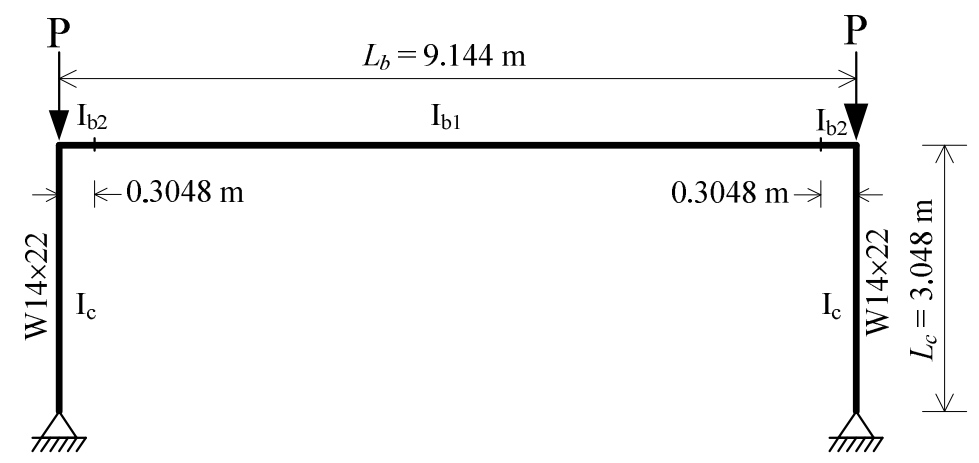

Figure 6. Frame with Semirigid Connections

When the columns are subjected to conservative forces $(\alpha=0)$, the present $K$-factors are compared with one obtained by Cheong-Siat-Moy [39] in Table 4. Cheong-Siat-Moy [39] proposed a new design method employing a fictitious lateral load that was a fraction of the gravity loads. As can be seen in Table 4, the result from this Euler hyperbola curve is in good agreement with that from Cheong-Siat-Moy [39]. It can also be found that the inelastic effects decrease the $K$-factor by $16.6 \%$ and $15.6 \%$ for AISC-LRFD and Eurocode 3 curves, respectively. 
Table 4. $K$-factors for the Column of Frame with Semirigid Connections Subjected to Conservative Forces

\begin{tabular}{cccc}
\hline \multirow{2}{*}{ Cheong-Siat-Moy [39] } & \multicolumn{3}{c}{ This study } \\
\cline { 2 - 4 } & Euler hyperbola & AISC-LRFD & Eurocode 3 \\
\hline 3.8 & 3.85 & 3.21 & 3.25 \\
\hline
\end{tabular}

Table 5 summarizes buckling loads and $K$-factors for columns with respect to $\alpha$. It is seen that the buckling load increases by tangential follower forces $(\alpha=1.0)$ by $269.8 \%$ for the elastic analysis. On the other hand, for the inelastic columns, the buckling loads increase by $23.1 \%$ and $25.6 \%$ for AISC-LRFD and Eurocode 3 curves, respectively, due to the tangential forces. In case of $K$-factors, as $\alpha$ increases, the $K$-factors converge to the value of 2.0 for both of the elastic and inelastic analyses. This $K$-factor of 2.0 corresponds to one in column with clamped boundary condition at the base, and the rotation fixed and translation free one at upper end. It is also seen that the tangential forces decrease $K$-factor by $48.1 \%$ for Euler hyperbola and $37.7 \%$ and $38.5 \%$ for AISC-LRFD and Eurocode 3 curves, respectively.

Table 5. Buckling Loads and $K$-factors for the Column of Frame with Semirigid Connections Subjected to Nonconservative Forces

\begin{tabular}{|c|c|c|c|c|c|c|c|}
\hline & \multirow{2}{*}{ Methods } & \multicolumn{6}{|c|}{ Nonconservativeness parameter $\alpha$} \\
\hline & & 0.0 & 0.2 & 0.4 & 0.6 & 0.8 & 1.0 \\
\hline \multirow{3}{*}{ Buckling loads } & Euler hyperbola & 1189.8 & 1402.0 & 1704.0 & 2164.9 & 2938.9 & 4399.7 \\
\hline & AISC-LRFD & 1021.7 & 1092.7 & 1158.0 & 1200.4 & 1235.3 & 1258.2 \\
\hline & Eurocode 3 & 1034.5 & 1125.8 & 1198.3 & 1245.0 & 1279.1 & 1299.1 \\
\hline \multirow{3}{*}{$K$-factors } & Euler hyperbola & 3.85 & 3.54 & 3.21 & 2.85 & 2.45 & 2.00 \\
\hline & AISC-LRFD & 3.21 & 2.87 & 2.58 & 2.34 & 2.15 & 2.00 \\
\hline & Eurocode 3 & 3.25 & 2.92 & 2.61 & 2.35 & 2.15 & 2.00 \\
\hline
\end{tabular}

Figure 7 shows buckling loads and inelastic effects on buckling loads with respect to $\alpha$. It is observed from Figure 7(a) that the buckling loads increase with increase of $\alpha$ and the elastic buckling load is smaller than the yield failure load at $0 \leq \alpha \leq 0.24$ and it is larger at $\alpha>0.24$. In Figure 7(b), $P_{c r}^{e}$ and $P_{c r}^{i}$ mean the buckling loads obtained from the elastic and inelastic analyses, respectively. The effects of inelasticity on buckling loads increase for increasing values of $\alpha$ by 71.4\% and $70.5 \%$ for AISC-LRFD and Eurocode 3, respectively. Figure 8 presents the variation of $K$-factors and the effects of inelasticity on $K$-factors. The $K$-factors decrease with increase of $\alpha$, as shown in Figure 8(a). In Figure 8(b), $K^{e}$ and $K^{i}$ are the $K$-factors evaluated from the elastic and inelastic analyses, respectively. It is observed from Figure $8(\mathrm{~b})$, the effects of inelasticity increase with increase of $\alpha$ and have the maximum values of $19.6 \%$ and $18.7 \%$ for AISC-LRFD and Eurocode 3 curves, respectively, at $\alpha=0.4$. These effects decrease thereafter and become to be zero at $\alpha=1.0$. 


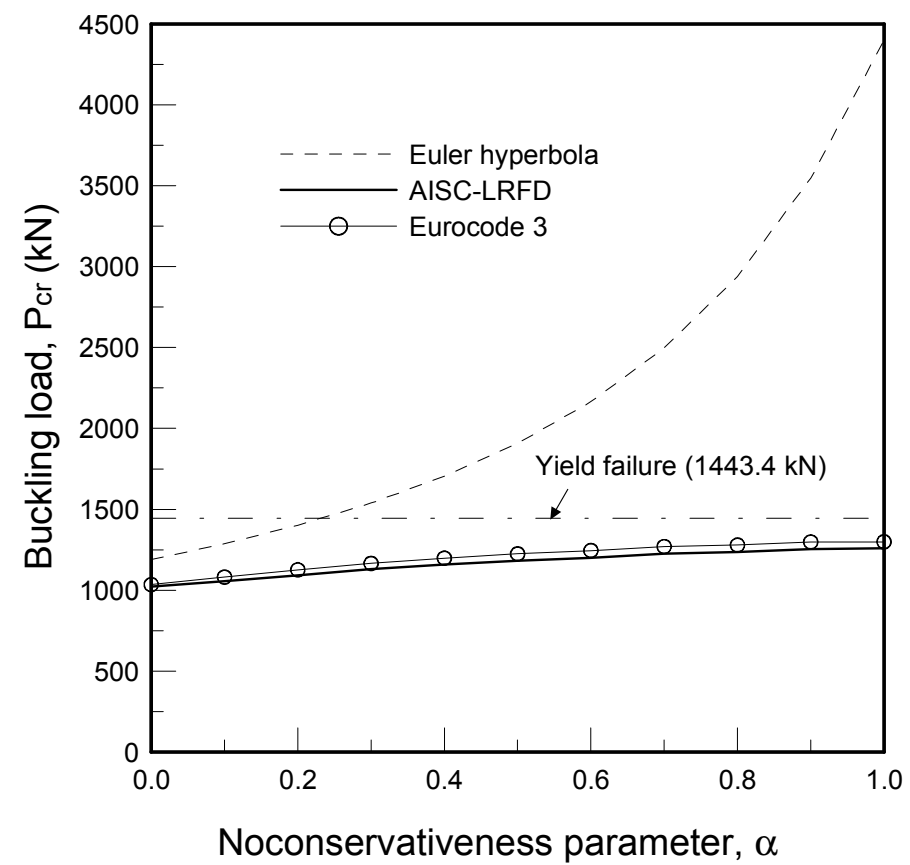

(a) Buckling loads

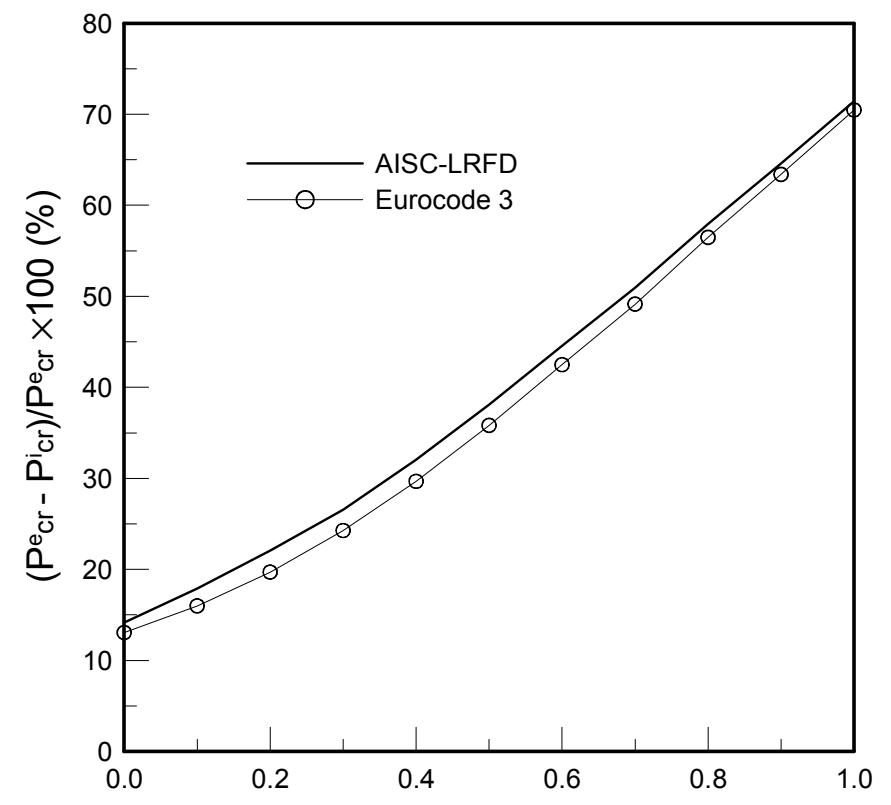

Nonconservativeness parameter, $\alpha$

(b) Effects of inelasticity on buckling loads

Figure 7. Buckling Loads and the Effects of Inelasticity on Buckling Loads for the Frame with Semirigid Connections with Respect to $\alpha$ 


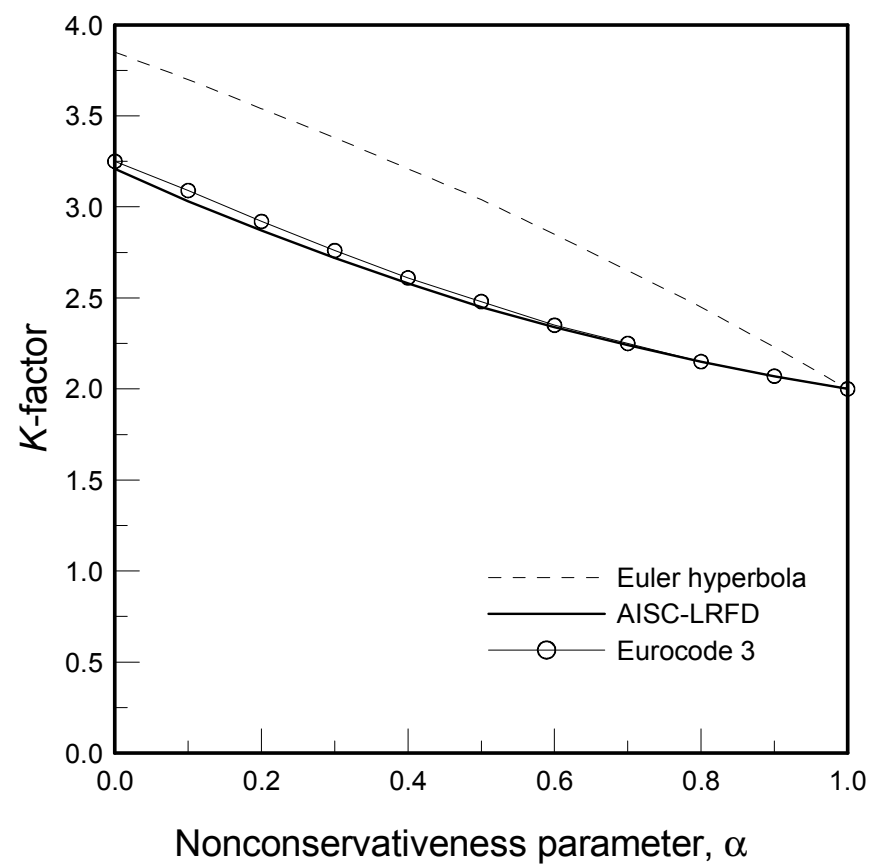

(a) $K$-factors

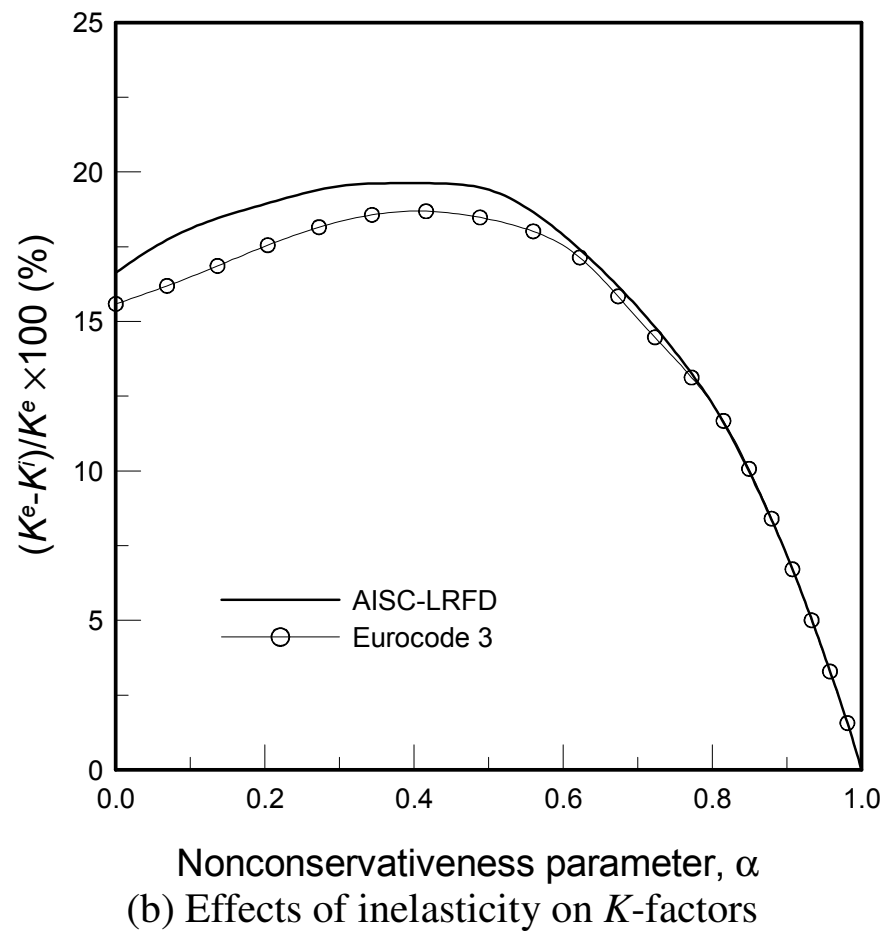

Figure 8. $K$-factors and the Effects of Inelasticity on $K$-factors for the Frame with Semirigid Connections with Respect to $\alpha$

Now for the frame with rigid connections $\left(I_{b 2}=I_{b 1}=83.25 \times 10^{-6} \mathrm{~m}^{4}\right)$ subjected to nonconservative forces, the variation of $K$-factors and the effects of inelasticity on $K$-factors are investigated with respect to various values of the stiffness ratio $I_{b} / I_{c}$ and the span ratio $L_{b} / L_{c}$ of beam to column. First, Figures 9(a) and 9(b) show the variation of $K$-factors with values of $\alpha$ versus the stiffness ratio for the Euler hyperbola and AISC-LRFD curves, respectively. In this example, we keep the moment of inertia of column $I_{c}$ constant and change the value of $I_{b}$. It is observed that $K$-factors from the present elastic and inelastic stability analyses decrease as $I_{b} / I_{c}$ increases and converge to the value 
of 2.0 after $I_{b} / I_{c}$ of 10 . This means that if the stiffness of the beam approaches infinity, the columns will behave like a member with a hinged boundary condition at the base, and a rotation fixed and translation free one at the upper end. The effects of inelasticity on $K$-factors are plotted in Figure 9(c) with respect to $I_{b} / I_{c}$ where $K^{A}$ is the $K$-factor evaluated from AISC-LRFD curve. It can also be seen that the $K$-factors from the inelastic analysis is smaller than those from elastic one except for $\alpha$ $=1.0$. It is interesting to observe from Figure 9(c) that the maximum values of inelastic effects are about $19.8 \%$ for whole $\alpha$ considered except for $\alpha=1.0$. The values of $I_{b} / I_{c}$ corresponding to the largest effects of inelasticity are on the decrease as $\alpha$ increases. This is due to the fact that as $\alpha$ increases, the total stiffness decreases, as shown in Eq. 5, and therefore the maximum inelastic effect occurs at the stiffness ratio with more flexible beam stiffness.

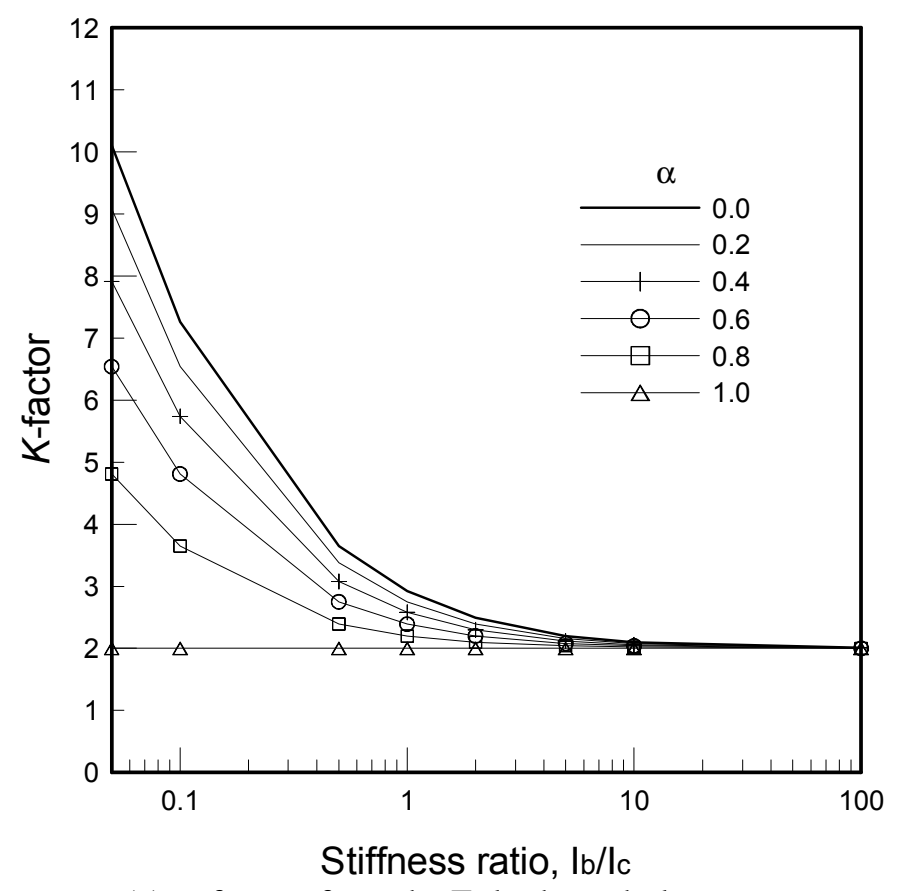

(a) $K$-factors from the Euler hyperbola curve

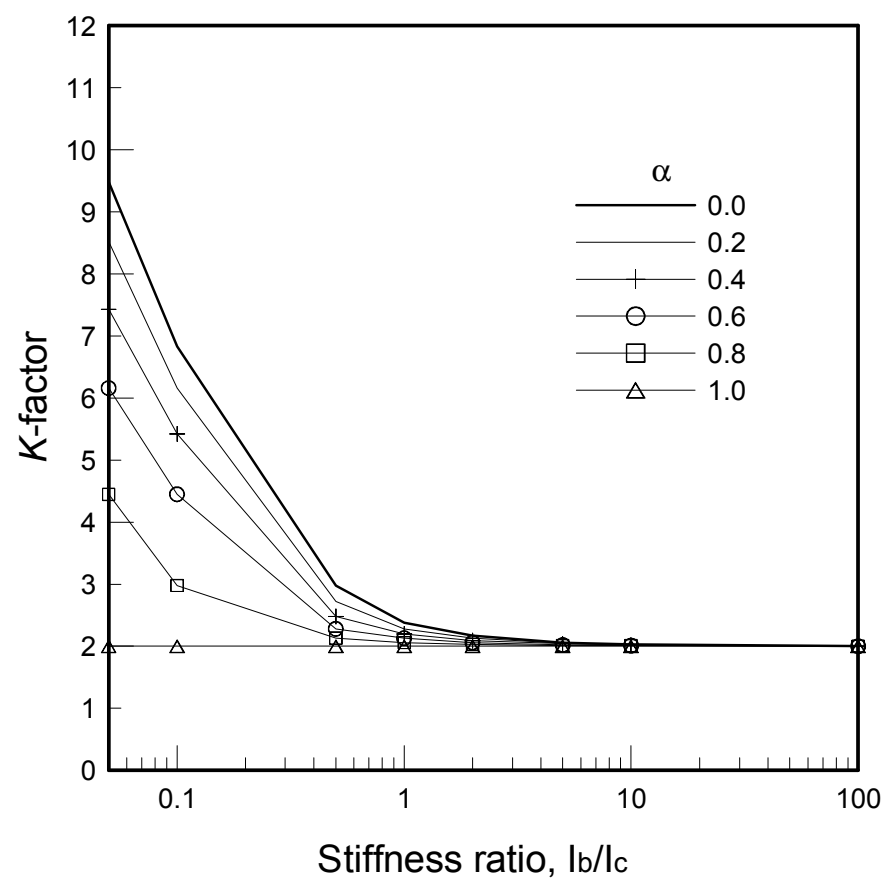

(b) $K$-factors from the AISC-LRFD curve 


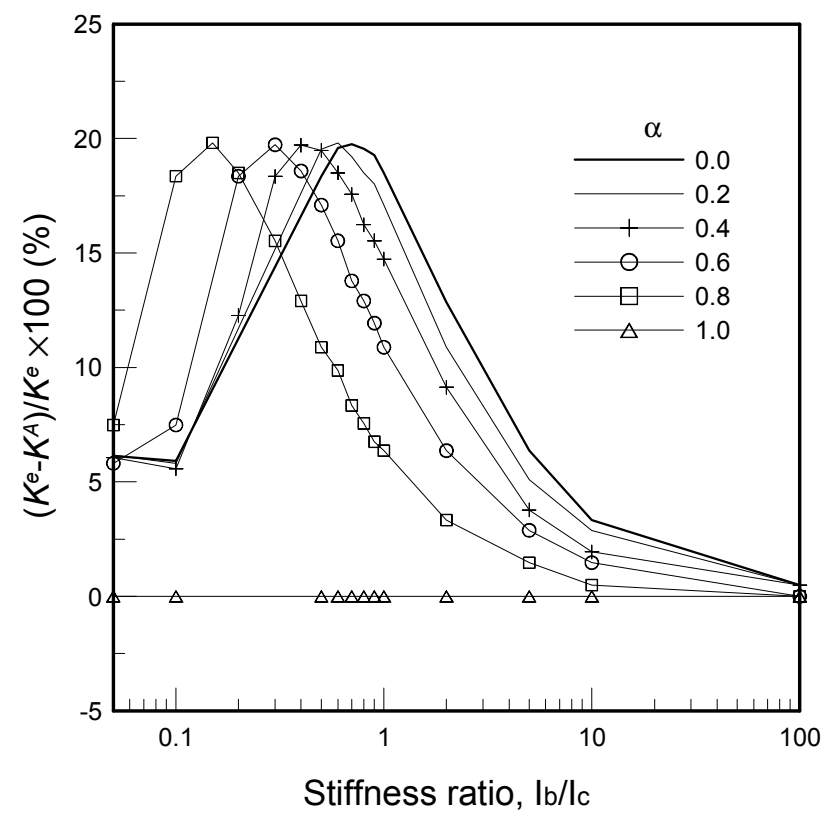

(c) Effects of inelasticity on $K$-factors

Figure 9. $K$-factors and the Effects of Inelasticity on $K$-factors for the Frame with Rigid Connections with Respect to $I_{b} / I_{c}$

Next, the variation of $K$-factors from the Euler hyperbola and AISC-LRFD curves are presented in Figures 10(a) and 10(b), respectively, with respect to the span ratio $L_{b} / L_{c}$ as the length of column remains constant and that of beam is varied. As can be seen, the $K$-factors for the frame subjected to tangential forces $(\alpha=1.0)$ are irrespective of $L_{b} / L_{c}$. It is interesting to observe that as $L_{b} / L_{c}$ increases, the $K$-factors decrease and have the minimum values at $L_{b} / L_{c}$ of 0.5 and increase thereafter for both of the Euler hyperbola and AISC-LRFD curves. As shown in Figure 10(c), the values of inelastic effects on $K$-factors increase with increase of $L_{b} / L_{c}$ and have the maximum value of $19.7 \%$ for whole $\alpha$ except $\alpha=1.0$, and decrease thereafter. The values of $L_{b} / L_{c}$ corresponding to the largest effects of inelasticity are on the increase as $\alpha$ increases.

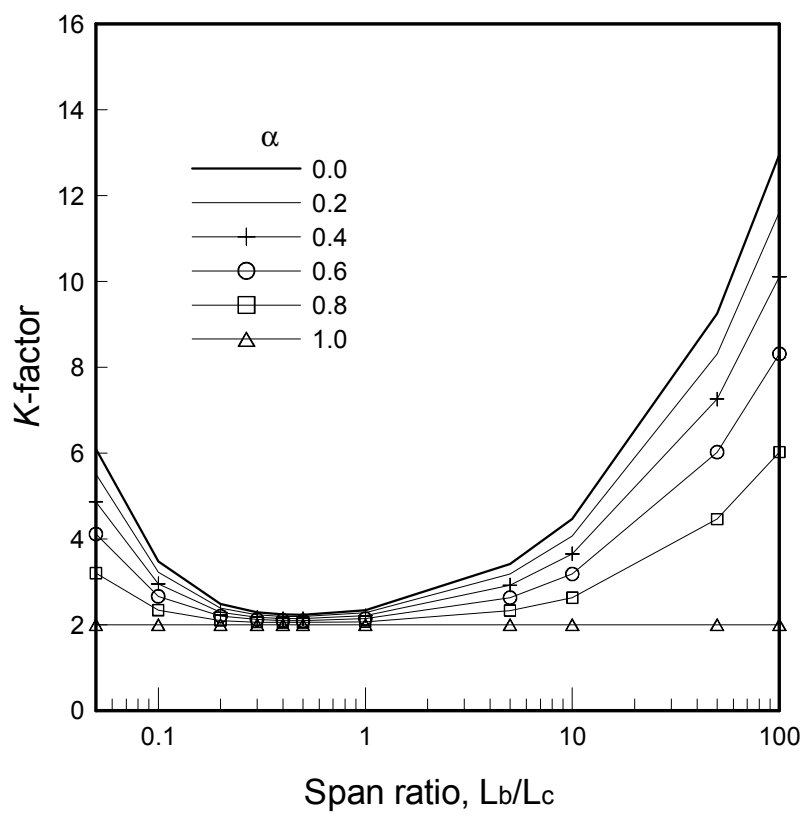

(a) $K$-factors from the Euler hyperbola curve 


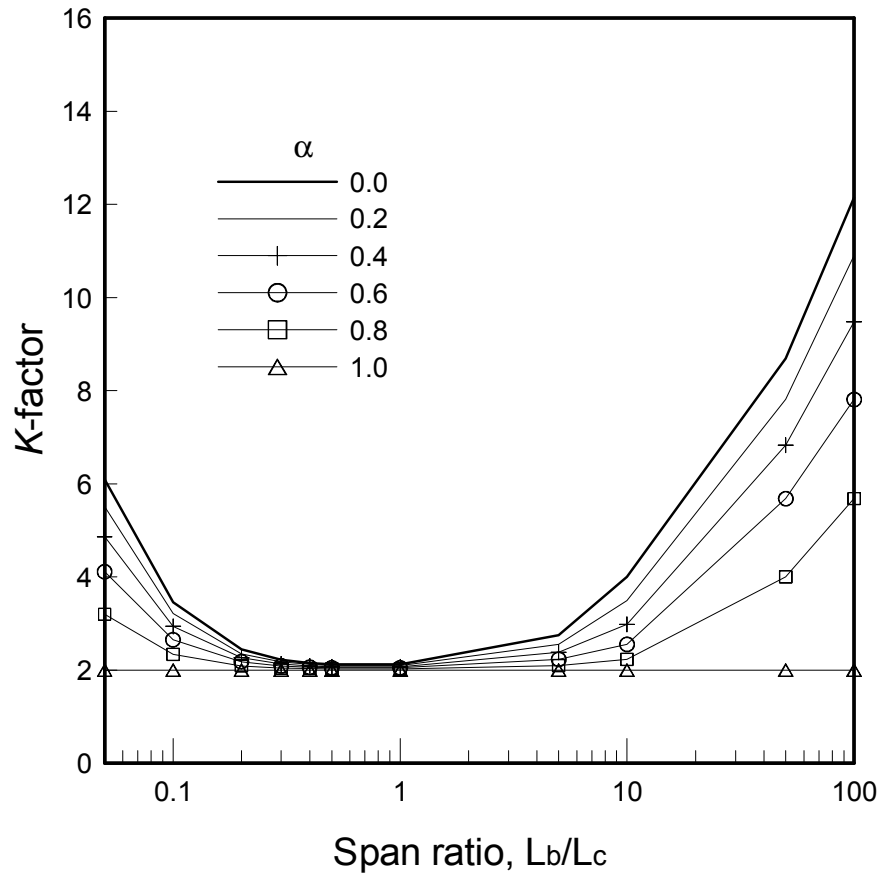

(b) $K$-factors from the AISC-LRFD curve

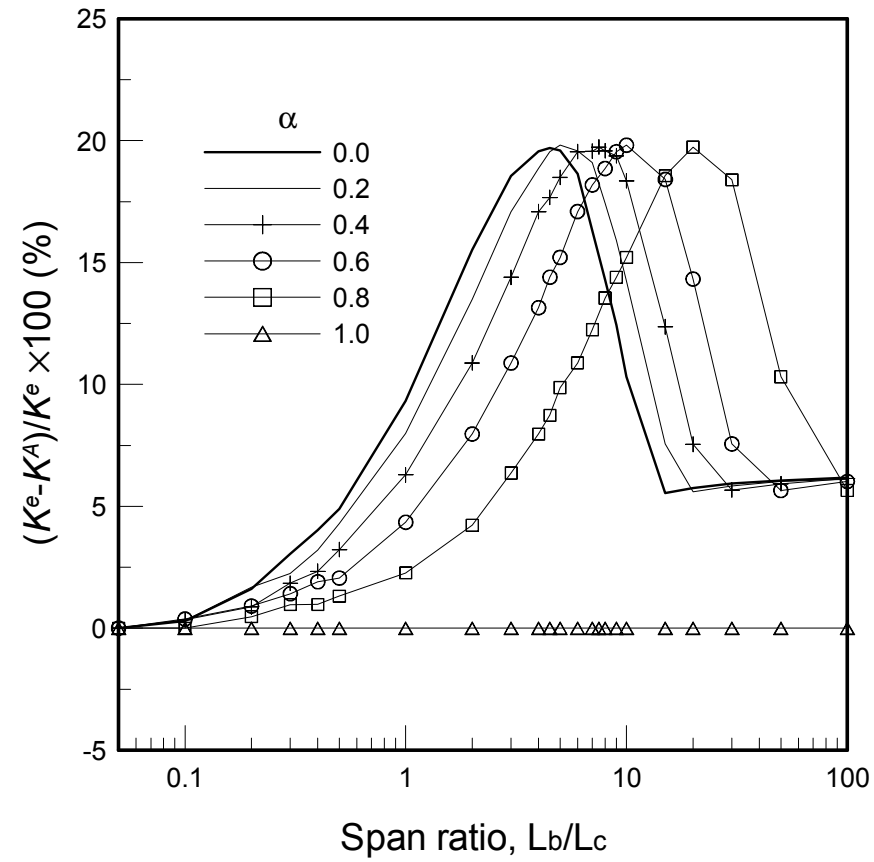

(c) Effects of inelasticity on $K$-factors

Figure 10. $K$-factors and the Effects of Inelasticity on $K$-factors for the Frame with Rigid Connections with Respect to $L_{b} / L_{c}$ 


\section{CONCLUSIONS}

The present paper proposes the inelastic system buckling analysis method to determine buckling loads and $K$-factors for columns of steel frames subjected to nonconservative forces by generalizing the iterative buckling procedures. This study overcomes the limit of traditional elastic and inelastic stability analyses using the many unrealistic assumptions which may lead to unreasonable $K$-factor if the frame structure does not satisfy these assumptions. Moreover this study is the first attempt to perform the stability analysis of the frame structures subjected to nonconservative forces considering column strength curve which considers the geometric imperfections and the residual stresses of the compression members. Throughout numerical examples, comparative examples and parametric studies are conducted and the following conclusions are drawn.

1) For evaluation of buckling loads and $K$-factors for the elastic conservative and nonconservative systems, the results by this study are in good agreement with those from other researchers.

2) For column subjected to the smaller axial force of in frame, the $K$-factor from inelastic analysis is larger than that from elastic analysis but it is the reverse for column subjected to the larger axial force.

3) For both elastic and inelastic analyses, the critical buckling loads of the frame increase with increase of $\alpha$, and so the conservative case $(\alpha=0)$ is the more susceptible of instability.

4) The increase ratio of the inelastic buckling load of the frame with respect to $\alpha$ is smaller than that of the elastic buckling load due to the significant degradation of the tangent modulus in inelastic analysis.

5) For all $\alpha$, the $K$-factors from the elastic and inelastic analyses decrease and converge to the specified value as $I_{b} / I_{c}$ increases.

6) The maximum values of inelastic effects on $K$-factors of the frame are same for all $\alpha$ considered except for $\alpha=1.0$ and the values of $I_{b} / I_{c}$ corresponding to the largest effects of inelasticity are on the decrease as $\alpha$ increases.

7) As $L_{b} / L_{c}$ increases, the $K$-factors have the minimum values at $L_{b} / L_{c}=0.5$ and increase thereafter for both elastic and inelastic analyses. The values of inelastic effects on $K$-factors increase with $L_{b} / L_{c}$ and have the same maximum values for whole range of $\alpha$.

\section{ACKNOWLEDGEMENTS}

This work is a part of a research project supported by the Korea Ministry of Land, Transportation Maritime Affairs (MLTM) through Core Research Project 1 of Super Long Span Bridge R\&D Center. The authors wish to express their gratitude for the financial support.

\section{REFERENCES}

[1] Julian, O.G. and Lawrence, L.S., "Notes on J and L Nomographs for Determination of Effective Lengths", Unpublished Report, Jackson and Moreland Engineers, Boston, 1959.

[2] AISC, Steel Construction Manual, 13th ed. American Institute of Steel Construction, Inc., Chicago, Illinois, 2005.

[3] ACI, Building Requirements for Structural Concrete, American Concrete Institute, Farmington Hill, MI, 2005.

[4] AASHTO, Load and Resistance Factor Design Specifications for Highway Bridges, 2nd ed., American Association of State Highway and Transportation Officials, Washington, DC, 1998. 
[5] Galambos, T.V., Structural Members and Frames, Prentice-Hall, New York, 1968.

[6] DIN 18800, Part 2: Analysis of Safety Against Buckling of Linear Members and Frames, Beuth Verlag GmbH, Berlin, 1990,

[7] Eurocode 3, Design of Steel Structures, Final Draft, CEN, Brussels, Belgium, 2002.

[8] Duan, L. and Chen, W.F., "Effective Length Factors for Columns in Unbraced Frames", Journal of Structural Engineering, ASCE, 1989, Vol. 115, pp. 149-165.

[9] Duan, L. and Chen, W.F., "Effective Length Factors for Columns in Braced Frames", Journal of Structural Engineering ASCE, 1988, Vol. 114, pp. 2357-2370.

[10] Bridge, R.Q. and Fraser, D., "Improved G-factor Method for Evaluating Effective Lengths of Columns", Journal of Structural Engineering, ASCE, 1987, Vol. 113, pp. 1341-1356.

[11] Mahini, M.R. and Seyyedian, H., "Effective Length Factor for Columns in Braced Frames Considering Axial Forces on Restraining Members", Structural Engineering and Mechanics, 2006, Vol. 22, pp. 685-700.

[12] Gantes, C.J. and Mageirou, G.E., "Improved Stiffness Distribution Factors for Evaluation of Effective Buckling Lengths in Multi-story Sway Frames", Engineering Structures, 2005, Vol. 27, pp. 1113-1124.

[13] Yura, J.A., "The Effective Length of Columns in Unbraced Frames", Engineering Journal, AISC, 1971, Vol. 8, pp. 37-42.

[14] LeMessurier, W.J., "A Practical Method of Second-order Analysis, Part 1: Pin-jointed Frames”, Engineering Journal, AISC, 1976, Vol. 13, pp. 89-96.

[15] LeMessurier, W.J., "A Practical Method of Second-order Analysis, Part 2: Rigid Frames", Engineering Journal, AISC, 1977, Vol. 14, pp. 49-67.

[16] Xu, L., Liu, Y. and Chen, J., "Stability of Unbraced Frames under Non-proportional Loading", Structural Engineering and Mechanics, 2001, Vol. 11, pp. 1-16.

[17] Liu, Y. and Xu, L., "Storey-based Stability Analysis of Multi-storey Unbraced Frames", Structural Engineering and Mechanics, 2005, Vol. 19, pp. 679-705.

[18] Özmen, G. and Girgin, K., "Buckling Lengths of Unbraced Multi-storey Frame Columns", Structural Engineering and Mechanics, 2005, Vol. 19, pp. 55-71.

[19] Girgin, K., Ozmen, G. and Orakdogen, E., "Buckling Lengths of Irregular Frame Columns", Journal of Constructional Steel Research, 2006, Vol. 62, pp. 605-613.

[20] Geschwindner, L.F., "A Practical look at Frame Analysis, Stability and Leaning Columns", Engineering Journal, AISC, 2002, Vol. 31, pp. 167-181.

[21] Roddis, W.M.K., Hamid, H.A. and Guo, C.Q., "K Factors for Unbraced Frames: Alignment Chart Accuracy for Practical Frame Variations", Engineering Journal, AISC, 1998, Vol. 8, pp. 81-93.

[22] Choi, D.H., Na, H.S., Jung, J.W. and Yoo, H., "Iterative Eigenvalue Analysis for Stability Design of Three-dimensional Frames Considering a Fictitious Axial Force Factor", International Journal of Steel structures, 2010, Vol. 10, pp. 325-335.

[23] Kim, H.D. and Lee, M.J., "Analytic Investigation of the P-Delta Effect of Middle-rise Unbraced Steel Frames", International Journal of Steel structures, 2010, Vol. 10, pp. 221-232.

[24] Essa, H.S., "New Stability Equation for Columns in Unbraced Frames", Structural Engineering and Mechanics, 1998, Vol. 6, pp. 411-425.

[25] Johnston, B.G., Structural Stability Research Council, Guide to Stability Design Criteria for Metal Structures, 3rd Ed., John Wiley \& Sons, Inc., New York.

[26] Bolotin, V.V., "Non-conservative Problems of the Theory of Elastic Stability", Pergamon Press, Oxford,1963.

[27] Gasparini, A.M., Saetta, A.V. and Vitaliani, R.V., "On the Stability and Instability Regions of Non- Conservative Continuous System under Partially Follower Forces”, Computer Methods in Applied Mechanics and Engineering, 1995, Vol. 124, pp. 63-78.

[28] Ryu, B.J., Sugiyama, Y., Yim, K.B. and Lee, G.S., "Dynamic Stability of An Elastically 
Restrained Column Subjected to Triangulary Distributed Subtangential Forces", Computers and Structures, 2000, Vol. 76, pp. 611-619.

[29] Wang, Q., "Effect of the Follower Force on the Static Buckling of Beams", International Journal of Structural Stability and Dynamics, 2002, Vol. 2, pp. 425-430.

[30] Imielowski, Sz., "Sensitivity Analysis of a Stepped Column under Circulatory Load", ZAMM, 1993, Vol. 73, pp. T186 -T189.

[31] Lee, J.S., Kim, N.I. and Kim, M.Y., "Sub-tangentially Loaded and Damped Beck's Columns on Two- Parameter Elastic Foundation”, Journal of Sound and Vibration, 2007, Vol. 306, pp. 766-789.

[32] Chen, W.F. and Lui, E.M., "Structural Members and Frames”, Elsevier Inc., New York, 1987.

[33] AISC, Manual of Steel Construction, 3rd ed., Load and Resistance Factor Design, American Institute of Steel Construction, Inc., Chicago, Illinois, 2001.

[34] Galambos, T.V., Guide to Stability Design Criteria for Metal Structures, 5th. ed., John Wiley and Sons, New York, 1998.

[35] Gardner, L. and Nethercot, D.A., Designers' Guide to EN 1993-1-1; Eurocode 3: Design of Steel Structures General Rules and Rules for Buildings, Thomas Telford Ltd, London, 2005.

[36] Rao, B.N. and Rao, G.V., "Applicability of the Static or the Dynamic Criterion for the Stability of a Cantilever Column under a Tip-concentrated Subtangential Follower Force", Journal of Sound and Vibration, 1987, Vol. 120, pp. 197-200.

[37] Leipholz, H., "Uber die befreiung der Ansatzfunktionen des Ritzschen und galerkinschen verfahrens von den Randbedingungen", Archive of Applied Mechanics (Ingenieur Archiv), 1967, Vol. 36, pp. 215-261 (in German).

[38] Kikuchi, F., “A Finite Element Method for Non-self-adjoint Problem”, International Journal for Numerical Methods in Engineering, 1973, Vol. 6, pp. 39-54.

[39] Cheong-Siat-Moy, F., "K-factor Paradox", Journal of Structural Engineering, 1986, Vol. 112, pp. 1747- 1760. 